\title{
Relationship Between Health-Promoting Lifestyle and Quality of Life in Women With Polycystic Ovarian Syndrome
}

\author{
Mojgan Mirghafourvand ${ }^{1}$, Sakineh Mohammad-Alizadeh Charandabi ${ }^{2}$, Tahereh Behroozi Lak ${ }^{3}$, \\ Fatemeh Aliasghari ${ }^{4^{*}}$
}

\begin{abstract}
Objectives: Promoting the quality of life in women with polycystic ovarian syndrome (PCOS) is one of the most important goals of the medical community and the importance of lifestyle is more apparent in this area. This study aimed to determine the relationship between health-promoting lifestyle and quality of life in women with PCOS.

Materials and Methods: This study was conducted on 174 women with PCOS who attended public and private fertility clinics in Urmia (west Azerbaijan, Iran). The participants were selected by convenience sampling method. The data were collected through socio-demographic, health-promoting lifestyle (HPLP-II) and quality of life (PCOSQ) questionnaires. Multivariate linear regression was used to determine the relationship between the independent variables (health-promoting lifestyle and socio-demographic characteristics) and the dependent variable (quality of life).

Results: The mean (standard deviation) of total score of the quality of life was obtained 45.8 (11.3) in the range between 0 to 100 . The highest and lowest mean scores were in the sub-domains of weight and hirsutism. The mean (SD) of total score of health-promoting lifestyle was $2.2(0.3)$ out of 4 . Based on multivariate linear regression, the variables of health responsibility, stress management, spiritual growth, body mass index (BMI), woman's job and menstrual cycle intervals were predictors of the quality of life in women with PCOS.

Conclusion: Given the importance of lifestyle in women with PCOS to maintain and improve their quality of life, it is necessary to take serious strategies for changing and improving their lifestyle.

Keywords: Health-promotion, Lifestyle, Polycystic Ovarian syndrome, Quality of life, Women
\end{abstract}

\section{Introduction}

Polycystic ovarian syndrome (PCOS) is one of the most common endocrine disorders (1) with multiple reproductive, hormonal and metabolic complexities determined as ovarian dysfunction and clinical or biochemical symptoms of hyperandrogenism and sonographic appearance of polycystic ovaries (2). Women with PCOS are at high risk of fertility problems, such as infertility, endometrial cancer, late menopause (3), and also metabolic disorders, such as dyslipidemia, type 2 diabetes mellitus and cardiovascular diseases (4). The main cause of this disorder is still unknown and researchers believe that there is no cure for this syndrome and available treatments just aim to improve its symptoms (5).

Quality of life is based on the perception of life and is quite subjective (6) as well as it is a multidimensional concept including physical, psychological and social aspects of health (7). According to the World Health Organization (WHO), 60\% of individual's quality of life depends on their attitude and lifestyle (8).
Health-promoting lifestyle includes behaviors that enable people to increase their control over their health and ultimately to improve their own and the society's health $(9,10)$. Health-promoting lifestyle is the foundation of long-lasting health (11). Since promoting the quality of life in women with PCOS is one of the most important goals of the medical community, the importance of lifestyle is more apparent in this area (12). A study by Clark et alon women with PCOS was conducted on the effect of lifestyle modification. The results showed that interventions improved the quality of life (13). Thomson et al studied lifestyle and quality of life in women with PCOS and reported that limiting energy to moderate level improves the quality of life, while doing exercise without proper diet has no greater benefits (14). Lifestyle modification is suggested as the first-line PCOS treatment (15). It has been reported that using appropriate lifestyle in women with PCOS has improved 75\% of problems (16).

Given that most patients are young women and that many factors can affect various aspects of their lives, 
it is necessary to modify lifestyle, maintain health and improve the quality of life in these women. Furthermore, no study has been conducted on the relationship between health-promoting lifestyle and quality of life in Iranian women with PCOS; therefore, we decided to evaluate the relationship between quality of life and health-promoting lifestyle in these women to take effective steps in improving their lifestyle and quality of life.

\section{Materials and Methods}

Study Population

This cross-sectional study was conducted on 174 women with PCOS who attended public and private fertility clinics in Urmia (capital of west Azerbaijan province, Iran) in 2015. The participants were selected according to the physician's final diagnosis of PCOS.

Inclusion criteria included diagnosis of PCOS based on medical records, willingness to participate in the study, being in reproductive age and having secondary school education and higher. Exclusion criteria included suffering from physical or mental diseases leading to limitations in health-promoting lifestyle, such as experiencing grief or other life events during the last three months, having special diets and having a history of depression.

\section{Sampling}

Sampling was performed in 2 private and 2 public centers in Urmia. Since convenience sampling was used, the researcher attended the mentioned centers and evaluated all the women who referred to the centers for various reasons such as amenorrhea, oligomenorrhea, hirsutism, ultrasound results indicating ovarian cysts, acne, infertility and so on. The participants were enrolled according to their medical record and the physician's final diagnosis of PCOS. Women who were willing to participate in the study were assessed in terms of eligibility criteria and if they were eligible, they signed the informed consent and were assured of confidentiality of all the information. Finally, they completed the questionnaires.

\section{Measures}

The data collection tools included socio-demographic and obstetrics, Health-Promoting Lifestyle Profile-II (HPLPII), and Polycystic Ovarian Syndrome Quality of Life (PCOSQ) questionnaires (see Supplementary file).

HPLP-II consists of 52 items containing 6 dimensions of health-promoting behaviors related to nutrition, physical activity, spiritual growth, health responsibility, stress management and interpersonal relationships. All items were scored based on Likert scale ranging from 1 to 4 ( 1 =never, 2 =sometimes, 3 =frequently, 4 =always) (17). Higher scores indicate higher health-promoting behaviors. Persian version of this tool was used in a study on women of reproductive age and Cronbach $\alpha$ and the intra-class correlation coefficient (ICC) have been reported 0.9 and 0.89 , respectively (18).
PCOSQ includes 26 items containing dimensions of emotions, hirsutism, weight, infertility and menstrual disorders. All items were scored based on Likert scale ranging from 1 (strongly/all of the time) to 7 (no problems/never) (19). Higher scores indicate better quality of life. Validity and reliability of the Persian version of questionnaire was confirmed by Amini et al (20).

The reliability of the HPLP-II and PCOSQ was determined by repeating the test-retest with a 2 -week interval on 20 women with PCOS through using the ICC assessment. The ICC was 0.96 for HPLP-II and 0.99 for PCOSQ.

\section{Sample Size and Statistical Methods}

Based on the parameter of quality of life and according to the results of the study by Amini et al (21), the sample size was calculated as 146 individuals (mean $=48.13$, standard deviation $[\mathrm{SD}]=29.69$, precision around the mean $=0.1$, $\alpha=95 \%$, and power $=90 \%$ ). Considering the $20 \%$ sample loss, the final sample size was calculated as 174 individuals.

Statistical analysis was performed in SPSS version 21.0 software. Normality of the quantitative data was confirmed by Skewness and Kurtosis. Descriptive statistics including frequency and mean (SD) were used to describe socio-demographic characteristics, quality of life and health-promoting lifestyle. Pearson correlation coefficient was used to determine the relationship between healthpromoting lifestyle and quality of life, and independent $t$ test and one-way analysis of variance (ANOVA) were used to determine the relationship between socio-demographic characteristics and quality of life, then all variables with $P<0.2$ based on bivariate analysis (Pearson correlation coefficient, independent $t$ test and one-way ANOVA) were entered into backward multivariate linear regression model to estimate the effect of each independent variables (health-promoting lifestyle and socio-demographic and obstetrics characteristics) on the dependent variable (quality of life) and to explain the variance.

\section{Results}

The socio-demographic and obstetric characteristics of participants were reported in Table 1. The mean (SD) score of the quality of life was 45.8 (11.3) out of 100 . The highest and lowest mean scores were obtained for weight (52.2 [30.6]) and hirsutism (37.7 [18.1]), respectively. The mean (SD) of total score of health-promoting lifestyle was obtained $2.2(0.3)$ out of 4 . Women obtained the highest mean score in nutrition $(2.9[0.5])$ and the lowest mean score in stress $(1.2[0.5])$. There was a statistically significant positive correlation between quality of life and total score of health-promoting lifestyle $(r=0.3 ; P<0.001)$ and all of its subdomains (except stress management) $(r=$ 0.2 to $0.3, P<0.05$ ) (Table 2 ).

In this study, body mass index (BMI), the first supporter, and menstrual cycle intervals showed a statistically significant relationship with quality of life $(P<0.05)$ (Table 
Table 1. The Relationship Between Socio-Demographic and Obstetrics Characteristics and Quality of Life in Women With PCOS Referred to Public and Private Clinics for Infertility in Urmia $(n=174)$

\begin{tabular}{|c|c|c|c|}
\hline Variable & Number & Mean (SD*) & $P$ Value \\
\hline \multicolumn{3}{|c|}{ Body Mass Index $\left(\mathrm{kg} / \mathrm{m}^{2}\right)$} & 0.001 \\
\hline $18.5-24.9$ & 43 & $54.4(10.9)$ & \\
\hline $25-29.9$ & 54 & $46.8(11.1)$ & \\
\hline$\geq 30$ & 77 & $40.2(8.2)$ & \\
\hline \multicolumn{3}{|l|}{ Ethnicity } & 0.194 \\
\hline Azeri & 99 & $46.2(11.3)$ & \\
\hline Kurd & 62 & $46.3(11.7)$ & \\
\hline Persian & 13 & $40.3(9.2)$ & \\
\hline \multicolumn{3}{|l|}{ Place of residence } & 0.663 \\
\hline City & 139 & $45.6(11.4)$ & \\
\hline Village & 35 & $46.5(11.3)$ & \\
\hline \multicolumn{3}{|l|}{ Marital status } & 0.005 \\
\hline Single & 40 & $42.4(7)$ & \\
\hline Married $^{\ddagger}$ & 134 & $46.8(12.2)$ & \\
\hline \multicolumn{3}{|l|}{ Having children } & 0.749 \\
\hline Yes & 53 & $46.3(10.8)$ & \\
\hline No & 81 & $47(13.1)$ & \\
\hline & 0.226 \\
\hline $\begin{array}{l}\text { Secondary school and } \\
\text { lower }\end{array}$ & 39 & $48.5(13.5)$ & \\
\hline Diploma & 58 & $44.6(9.3)$ & \\
\hline University & 37 & $47.5(12.3)$ & \\
\hline \multicolumn{3}{|c|}{ Mean length of menstruation } & 0.295 \\
\hline$<3$ Days & 40 & $43.7(7.8)$ & \\
\hline 3-7 Days & 108 & $46.8(12.3)$ & \\
\hline > 7 Days & 26 & $44.6(11.9)$ & \\
\hline \multicolumn{3}{|c|}{ Mean interval between two consecutive menstruation } & 0.001 \\
\hline$<21$ Days & 22 & $45.6(11.3)$ & \\
\hline $21-35$ Days & 48 & $51.6(11.4)$ & \\
\hline > 35 Days & 104 & $43.1(10.4)$ & \\
\hline \multicolumn{3}{|c|}{ Amount of bleeding in menstruation } & 0.758 \\
\hline Slight & 46 & $45.3(8.9)$ & \\
\hline Average & 86 & $45.9(13.4)$ & \\
\hline Severe & 28 & $47.3(8.7)$ & \\
\hline Very severe & 14 & $43.4(10.4)$ & \\
\hline \multicolumn{3}{|l|}{ Spouse's job } & 0.514 \\
\hline Working ${ }^{\S}$ & 40 & $45.9(12.4)$ & \\
\hline Employee & 26 & $48.4(10.3)$ & \\
\hline Shopkeeper & 31 & $48.2(10.1)$ & \\
\hline Other $^{* *}$ & 37 & $44.7(12.6)$ & \\
\hline \multicolumn{3}{|l|}{ Women's education } & 0.354 \\
\hline Middle school & 28 & $47.9(12.5)$ & \\
\hline Diploma & 97 & $44.7(11)$ & \\
\hline Collegiate & 49 & $46.6(11.3)$ & \\
\hline \multicolumn{3}{|l|}{ Women's job } & 0.139 \\
\hline Housewife & 109 & $46.7(12.7)$ & \\
\hline Employee & 65 & $44.3(8.5)$ & \\
\hline \multicolumn{3}{|c|}{ Adequacy of monthly income for living expenses } & 0.742 \\
\hline Not at all & 54 & $46.4(11.1)$ & \\
\hline Somewhat & 94 & $45.8(11.8)$ & \\
\hline Completely & 26 & $44.3(10.5)$ & \\
\hline \multicolumn{3}{|c|}{ The role of perceived stress due to PCOS in life } & 0.744 \\
\hline Less effective & 44 & $45.3(10.4)$ & \\
\hline Quite impressive & 130 & $45.9(11.7)$ & \\
\hline \multicolumn{3}{|l|}{ Woman's first supporter } & 0.001 \\
\hline Mother, father or both & 64 & $40.5(7.3)$ & \\
\hline
\end{tabular}

\section{Table 1. Continued}

\begin{tabular}{|c|c|c|c|}
\hline Spouse & 84 & $49.3(12.7)$ & \\
\hline Other ${ }^{+}$ & 26 & $47.1(10.2)$ & \\
\hline \multicolumn{3}{|c|}{ Satisfaction with sexual relationship } & 0.163 \\
\hline Dissatisfied & 21 & $46.7(16.3)$ & \\
\hline Rarely satisfied & 68 & $44.9(9.8)$ & \\
\hline Fully satisfied & 44 & $49.2(11.2)$ & \\
\hline \multicolumn{3}{|c|}{$\begin{array}{l}\text { Suffering from infertility or having a history of } \\
\text { infertility }{ }^{\S \S}\end{array}$} & 0.867 \\
\hline No & 38 & $46.5(11.4)$ & \\
\hline Yes & 96 & $46.9(12.5)$ & \\
\hline \multicolumn{3}{|c|}{ Evaluation for infertility in the past ${ }^{\S \S}$} & 0.973 \\
\hline No & 64 & $46.8(11.4)$ & \\
\hline Yes & 70 & $46.7(12.9)$ & \\
\hline \multicolumn{3}{|c|}{ Active efforts to become pregnant ${ }^{\S \S}$} & 0.640 \\
\hline$<9$ months & 102 & $44.5(10.6)$ & \\
\hline$>9$ months & 32 & $48.3(12.4)$ & \\
\hline
\end{tabular}

* Standard Deviation; ${ }^{\star}$ One participant was widowed; ${ }^{\S} 7$ people were unemployed; 'Including support from friends, relatives or medical staff; $\S \S$ In married women.

1). The variables of BMI, ethnicity, marital status, woman's job, the first supporter, sexual satisfaction and menstrual cycle intervals that had $P<0.2$ and also health-promoting lifestyle and its subdomains were entered into backward multiple linear regression model that resulted in exclusion of total health-promoting lifestyle, nutrition, physical activity, interpersonal relationships, marital status, ethnicity, first supporter and sexual satisfaction. Health responsibility, stress management, spiritual growth, BMI, woman's job and menstrual cycle intervals remained in the model and explained $39.1 \%$ of the variance of the quality of life (Table 3 ).

\section{Discussion}

This was the first study in Iran to evaluate healthpromoting behaviors and its relationship with the quality of life among women with PCOS. The results showed a moderate total score for health-promoting lifestyle and the quality of life. Health responsibility, stress management, spiritual growth, BMI, woman's job and menstrual cycle intervals were predictors of quality of life.

The results indicated that quality of life in women with PCOS was moderate that is consistent with other studies in Iran (21) and America (22) conducted on women with PCOS. The concerns of these women about infertility issues and health risks associated with this syndrome have had negative effects on their quality of life. Nicandri and Hoeger suggested that it is important to modify lifestyle as the first-line treatment and proceed with interventions and treatments without delay to improve their health in the long term (23).

In this study, one of the predictors of quality of life was health responsibility which had a significant correlation with the quality of life, such that increased health responsibility improved their quality of life. According to the results of a study conducted in Teheran, Iran, from 
Table 2. Total Score of Health-promoting Lifestyle- II and its Dimensions and Their Relationship With Quality of Life in Women With PCOS Referred to Public and Private Clinics for Infertility in Urmia $(n=174)$

\begin{tabular}{|c|c|c|c|c|}
\hline Variable & Mean (SD) & Obtainable Range & Obtained Practical Range & Correlated With Quality of Life, $r(P)$ \\
\hline Health-promoting lifestyle- II & $2.2(0.3)$ & 1 to 4 & 1.6 to 3.2 & $0.3(<0.001)$ \\
\hline Nutrition & $2.9(0.5)$ & 1 to 4 & 1.9 to 4.2 & $0.2(0.012)$ \\
\hline Interpersonal relationships & $2.4(0.5)$ & 1 to 4 & 1.4 to 3.7 & $0.3(<0.001)$ \\
\hline Health responsibility & $2.6(0.4)$ & 1 to 4 & 1.2 to 3.9 & $0.2(0.006)$ \\
\hline Physical activity & $1.6(0.5)$ & 1 to 4 & 1 to 2.9 & $0.3(<0.001)$ \\
\hline Stress management & $1.2(0.5)$ & 1 to 4 & 1.1 to 3.6 & $0.1(0.161)$ \\
\hline Spiritual growth & $2.2(0.6)$ & 1 to 4 & 1 to 3.7 & $0.3(<0.001)$ \\
\hline Quality of Life & $45.8(11.3)$ & 0 to 100 & 20.9 to 84.6 & _ \\
\hline
\end{tabular}

Abbreviation: SD, standard deviation.

Table 3. The Predictors of Quality of Life in Women With PCOS Referred to Public and Private Clinics for Infertility in Urmia $(n=174)$

\begin{tabular}{|c|c|c|}
\hline Variable & B (Cl 95\%) & $P$ Value \\
\hline Health responsibility & 4.5 (1.1 to 7.9$)$ & 0.009 \\
\hline Stress management & $-5.6(-9.3$ to -2.0$)$ & 0.003 \\
\hline Spiritual growth & 6.3 (3.3 to 9.3 ) & $<0.001$ \\
\hline \multicolumn{3}{|l|}{ Body mass index } \\
\hline 18.5-24.9 (Ref) & 0 & \\
\hline $25-29.9$ & $-6.6(-10.2$ to -3.0$)$ & $<0.001$ \\
\hline$\geq 30$ & $-12.2(-15.6$ to -8.8$)$ & $<0.001$ \\
\hline \multicolumn{3}{|l|}{ Women's job } \\
\hline Employed (Ref) & 0 & \\
\hline Housewife & $2.7(-0.2$ to 5.5$)$ & 0.064 \\
\hline \multicolumn{3}{|c|}{ Mean interval between 2 consecutive menstruation } \\
\hline 21-35 days (Ref) & 0 & \\
\hline$<21$ days & $-3.0(-7.7$ to 1.7$)$ & 0.214 \\
\hline$>35$ days & $-5.7(-8.9$ to -2.5$)$ & 0.001 \\
\hline
\end{tabular}

Adjusted R2= $39.1 \%$

Iranian women's perspective, health preservation was known as a personal obligation, thus women have realized the importance of prevention and consider themselves responsible for their health preservation (9). The effect of responsibility is such that not only the physician is responsible for individual's health, but also the individual obtains necessary knowledge about her disease and shares it with her physician, and as such is involved in management of her health (24).

In this study, increased mean score of spiritual growth increased women's quality of life. The spiritual aspect is an important aspect of human function and positively influences the health (25). In this study, overweight and obese women compared to women with normal BMI (18.5 to 24.9) had lower quality of life. Weight loss is absolutely vital in the treatment of PCOS but the support given to PCOS patients to help reduce their weight is not adequate and more measures are needed for improvement in this area (26).

In this study, housewives had a better quality of life than employed women. However, the results of a research suggested that employed women had a better quality of life than housewives (27). In contrast, a study suggested that employed women are not superior to housewives except for physical dimension (28). In this case, a study suggests that there is no significant difference between employed women and housewives in terms of the quality of life; however, the study recommended that measures be taken to improve housewives' quality of life (29).

Irregular menstrual cycles were also a predictor of quality of life in these women, as women with menstrual cycle disorders experienced lower quality of life than women with normal menstrual cycles. This result is consistent with 2 studies conducted in Malaysia (30) and Hong Kong (31), in which menstrual disorders in women affected health-related quality of life. Likewise, a study conducted in Michigan and East Tennessee State University reported that after obesity, menstrual disorders lead to decreased quality of life in these women (5). In contrast, according to a study conducted in Germany on women with PCOS compared with healthy women to determine the effect of PCOS symptoms on quality of life, including mental health and sexual satisfaction, a variety of menstrual disorders and even infertility did not affect the mental health of these women (32). The emotional consequences of infertility are modulated by several factors such as the ethnic, cultural and societal context (33). In addition, as the infertility and irregular menstrual cycles are more important in married women, the cause of the observed contrast may probably be due to difference in marital status of participants in the present study and the study conducted in Germany. In our study, only about one-fifth of participants (22.98) were single but in the above mentioned study, half of women (50\%) were single.

Given the above, controlling BMI and regulating their menstrual cycles can lead to better quality of life in women with PCOS. Furthermore, the quality of life of these women can be greatly improved by strengthening their sense of responsibility and spiritual growth while managing their stress.

Using of valid and standard questionnaires is the 
strength of this study. Given that this is a cross-sectional study, the relationship shown between quality of life and dimensions of health-promoting lifestyle and some socio-demographic and obstetric characteristics do not necessarily indicate a causal relationship. Also, the method of sampling is another limitation of this study that reduces the generalizability of the findings. According to the results, it is recommended that barriers and facilitators of health-promoting lifestyle be explained from the perspective of women with PCOS so that solutions can be adopted to overcome barriers and to strengthen facilitators, and hence the quality of life can be improved in these women.

\section{Conclusion}

The results show that the score of health-promoting lifestyle and quality of life of women with PCOS is moderate. There is a significant relationship between health-promoting lifestyle and quality of life. Some sociodemographic variables such as BMI, woman's job and menstrual cycle intervals are also predictors of quality of life in these women. Therefore, a holistic approach should be considered to improve the quality of life for these women and all factors affecting the quality of life should be taken into account to prevent the disease complications.

\section{Ethical issues}

The Ethics Committee of Tabriz University of Medical Sciences approved the study (Ethical code No. TBZMED. REC.1394.341).

\section{Conflict of Interests}

We hereby declare that there is no conflict of interests.

\section{Financial Support}

This study was approved and funded by Tabriz University of Medical Sciences, Tabriz, Iran.

\section{Acknowledgments}

We greatly appreciate the cooperation and assistance provided by the Research Deputy of the University and all employees in Shahid Motahari Hospital, Urmia and gynecologists in the hospital and all related centers.

\section{Supplementary Materials}

Supplementary file contains Health-Promoting Lifestyle Profile II and Polycystic Ovary Syndrome Questionnaire (PCOSQ) questionnaires.

\section{References}

1. Kauffman RP, Baker TE, Baker VM, DiMarino P, Castracane VD. Endocrine and metabolic differences among phenotypic expressions of polycystic ovary syndrome according to the 2003 Rotterdam consensus criteria. Am J Obstet Gynecol. 2008;198(6):670.e671-677. e677-610. doi:10.1016/j.ajog.2008.01.037

2. Fauser BC, Tarlatzis BC, Rebar RW, et al. Consensus on women's health aspects of polycystic ovary syndrome (PCOS): the Amsterdam ESHRE/ASRM-Sponsored 3rd PCOS Consensus Workshop Group. Fertil Steril. 2012;97(1):28-38.e25. doi:10.1016/j.fertnstert.2011.09.024

3. Tehrani FR, Solaymani-Dodaran M, Hedayati M, Azizi F. Is polycystic ovary syndrome an exception for reproductive aging? Hum Reprod. 2010;25(7):1775-1781. doi:10.1093/ humrep/deq088

4. El-Mazny A, Abou-Salem N, El-Sherbiny W, El-Mazny A. Insulin resistance, dyslipidemia, and metabolic syndrome in women with polycystic ovary syndrome. Int J Gynaecol Obstet. 2010;109(3):239-241. doi:10.1016/j.ijgo.2010.01.014

5. McCook JG, Reame NE, Thatcher SS. Health-related quality of life issues in women with polycystic ovary syndrome. J Obstet Gynecol Neonatal Nurs. 2005;34(1):1220. doi:10.1177/0884217504272945

6. Mirghafourvand M, Mohammad-Alizadeh Charandabi S, Asghari Jafarabadi M, Tavananezhad N, Karkhane M. Predictors of health-related quality of life in Iranian women of reproductive age. Appl Res Qual Life. 2016;11(3):723737. doi: $10.1007 /$ s11482-015-9392-0

7. Colwell HH, Mathias SD, Pasta DJ, Henning JM, Steege JF. A health-related quality-of-life instrument for symptomatic patients with endometriosis: a validation study. Am J Obstet Gynecol. 1998;179(1):47-55.

8. The WHO cross-national study of health behavior in school-aged children from 35 countries: findings from 2001-2002. J Sch Health. 2004;74(6):204-206.

9. Baheiraei A, Mirghafourvand M, Charandabi SM, Mohammadi E. Facilitators and Inhibitors of Healthpromoting Behaviors: The Experience of Iranian Women of Reproductive Age. Int J Prev Med. 2013;4(8):929-939.

10. Baheiraei A, Mirghafourvand M, Mohammadi E, Charandabi SM. The experiences of women of reproductive age regarding health-promoting behaviours: a qualitative study. BMC Public Health. 2012;12:573. doi:10.1186/14712458-12-573

11. Hackett TP, Cassem NH. Factors contributing to delay in responding to the signs and symptoms of acute myocardial infarction. Am J Cardiol. 1969;24(5):651-658.

12. Hoeger KM. Role of lifestyle modification in the management of polycystic ovary syndrome. Best Pract Res Clin Endocrinol Metab. 2006;20(2):293-310. doi:10.1016/j. beem.2006.03.008

13. Clark AM, Thornley B, Tomlinson L, Galletley C, Norman RJ. Weight loss in obese infertile women results in improvement in reproductive outcome for all forms of fertility treatment. Hum Reprod. 1998;13(6):1502-1505.

14. Thomson RL, BuckleyJD, Lim SS, et al.Lifestyle management improves quality of life and depression in overweight and obese women with polycystic ovary syndrome. Fertil Steril. 2010;94(5):1812-1816. doi:10.1016/j.fertnstert.2009.11.001

15. Moran LJ, Hutchison SK, Norman RJ, Teede HJ. Lifestyle changes in women with polycystic ovary syndrome. Cochrane Database Syst Rev. 2011(2):Cd007506. doi:10.1002/14651858.CD007506.pub2

16. Hoeger K, Davidson K, Kochman L, Cherry T, Kopin L, Guzick DS. The impact of metformin, oral contraceptives, and lifestyle modification on polycystic ovary syndrome in obese adolescent women in two randomized, placebocontrolled clinical trials. J Clin Endocrinol Metab. 2008;93(11):4299-4306. doi:10.1210/jc.2008-0461

17. Walker SN, Sechrist KR, Pender NJ. The Health-Promoting 
Lifestyle Profile: development and psychometric characteristics. Nurs Res. 1987;36(2):76-81.

18. Mirghafourvand M, Baheiraei A, Nedjat S, Mohammadi E, Charandabi SM, Majdzadeh R. A population-based study of health-promoting behaviors and their predictors in Iranian women of reproductive age. Health Promot Int. 2015;30(3):586-594. doi:10.1093/heapro/dat086

19. Cronin L, Guyatt G, Griffith L, et al. Development of a health-related quality-of-life questionnaire (PCOSQ) for women with polycystic ovary syndrome (PCOS). J Clin Endocrinol Metab. 1998;83(6):1976-1987. doi:10.1210/ jcem.83.6.4990

20. Amini L, Ghorbani B, Montazeri A. Iranian version of health-related quality of life for women with polycystic ovary syndrome (PCOSQ): translation, reliability and validity. Payesh. 2012;11(2):227-233.

21. Amini L, Ghorbani B, Montazeri A, et al. Quality of life for women with polycystic ovary syndrome. Payesh. 2012;11(6):857-862.

22. Trent ME, Rich M, Austin SB, Gordon CM. Fertility concerns and sexual behavior in adolescent girls with polycystic ovary syndrome: implications for quality of life. J Pediatr Adolesc Gynecol. 2003;16(1):33-37.

23. Nicandri KF, Hoeger K. Diagnosis and treatment of polycystic ovarian syndrome in adolescents. Curr Opin Endocrinol Diabetes Obes. 2012;19(6):497-504. doi:10.1097/MED.0b013e32835a1a03

24. Avery JC, Braunack-Mayer AJ. The information needs of women diagnosed with Polycystic Ovarian Syndrome-implications for treatment and health outcomes. BMC Womens Health. 2007;7:9. doi:10.1186/1472-6874-7-9

25. Sehhatie F, Mirghafourvand M, Momeni K. Health promoting behaviors among postmenopausal women in langroud city, Iran. Int J Womens Health Reprod Sci. 2015;3(3):158-162. doi: 10.15296/ijwhr.2015.33

26. Humphreys L, Costarelli V. Implementation of dietary and general lifestyle advice among women with polycystic ovarian syndrome. J R Soc Promot Health. 2008;128(4):190195.

27. Vahdaninia M, Goshtasbi A, Montazeri A, Maftoun F. Health-related quality of life in an elderly population in Iran: a population-based study. Payesh. 2005;4(2):113-120.

28. Reisine S, Fifield J, Walsh S, Dauser D. Employment and quality of life outcomes among women with fibromyalgia compared to healthy controls. Women Health. 2004;39(4):119. doi:10.1300/J013v39n04_01

29. Saravi FK, Navidian A, Rigi SN, Montazeri A. Comparing health-related quality of life of employed women and housewives: a cross sectional study from southeast Iran. BMC Womens Health. 2012;12:41. doi:10.1186/1472-6874$12-41$

30. Nur Azurah AG, Sanci L, Moore E, Grover S. The quality of life of adolescents with menstrual problems. J Pediatr Adolesc Gynecol. 2013;26(2):102-108. doi:10.1016/j. jpag.2012.11.004

31. Chung PW, Chan SS, Yiu KW, Lao TT, Chung TK. Menstrual disorders in a Paediatric and Adolescent Gynaecology Clinic: patient presentations and longitudinal outcomes. Hong Kong Med J. 2011;17(5):391-397.

32. Hahn S, Janssen OE, Tan S, et al. Clinical and psychological correlates of quality-of-life in polycystic ovary syndrome. Eur J Endocrinol. 2005;153(6):853-860. doi:10.1530/ eje.1.02024

33. al Ma'aitah R, Haddad L, Umlauf MG. Health promotion behaviors of Jordanian women. Health Care Women Int. 1999;20(6):533-546. doi:10.1080/073993399245449

Copyright ( 2017 The Author (s); This is an open-access article distributed under the terms of the Creative Commons Attribution License (http://creativecommons.org/licenses/by/4.0), which permits unrestricted use, distribution, and reproduction in any medium, provided the original work is properly cited. 